Article

\title{
Developing a Participatory Planning Support System for Sustainable Regional Planning-A Problem Structuring Case Study
}

\author{
Dina Margrethe Aspen ${ }^{1, *(1)}$ and Andreas Amundsen ${ }^{2}$ (D) \\ 1 Department of International Business, Norwegian University of Science and Technology, \\ 6009 Ålesund, Norway \\ 2 United Future Lab Norway, 6009 Ålesund, Norway; Andreas.Amundsen@alesund.kommune.no \\ * Correspondence: dina.aspen@ntnu.no
}

Citation: Aspen, D.M.; Amundsen,

A. Developing a Participatory

Planning Support System for Sustainable Regional Planning-A

Problem Structuring Case Study.

Sustainability 2021, 13, 5723. https://

doi.org/10.3390/su13105723

Academic Editor: Åsa Gren

Received: 31 March 2021

Accepted: 17 May 2021

Published: 20 May 2021

Publisher's Note: MDPI stays neutral with regard to jurisdictional claims in published maps and institutional affiliations.

Copyright: (c) 2021 by the authors. Licensee MDPI, Basel, Switzerland. This article is an open access article distributed under the terms and conditions of the Creative Commons Attribution (CC BY) license (https:/ / creativecommons.org/licenses/by/ $4.0 /)$.

\begin{abstract}
In this paper, we report on the application of systems engineering in initiating the synthesis of a participatory planning support system (PSS) for sustainable regional planning. The systems engineering SPADE approach is applied in a model-based fashion to define and link sustainable development goals (SDGs) to regional and urban planning policies in a co-creative multi-stakeholder environment. The approach is demonstrated through a case study from the interregional climate, land-use, and transportation planning process (PAKT) in the Ålesund region in Norway. The work was performed using focus groups with planning stakeholders over a series of workshops to analyze, design, verify and validate the problem structure. Our study shows that the approach is useful for integrating and operationalizing the SDGs in a planning context. The methodology also brings clarity and structure to planning problems and provides a pedagogical frame to engage stakeholders in co-creative PSS synthesis. Further research is necessary to explore how structured elements may be exploited in PSS synthesis.
\end{abstract}

Keywords: regional and urban planning; sustainable development goals; planning support systems; systems engineering

\section{Introduction}

Integrating the Sustainable Development Goals (SDGs) in regional and urban planning is critical for goal attainment. The Organisation for Economic Co-operation and Development (OECD) estimates that 105 out of the 160 SDG targets will not be achieved without engagement at the sub-national level [1], and all SDGs have targets related to responsibilities at the local and regional level. This integration process is often referred to as "localizing", and urban and regional planning are considered critical processes in which this integration must occur [2]. Literature is abundant with case reports from various localizing efforts, where municipal and regional authorities have attempted to use the goals in creating visions, strategies, and plans (see, e.g., [3,4]). These efforts show that successful integration must be performed systematically [5], building on a coherent and holistic approach [6] tailored to the local context and plans [7].

While there currently exists a wide range of planning support systems (PSSs) [8-10], their common objective is to assist planning practitioners and other stakeholders in accessing, assessing, and communicating information and knowledge in the planning process. Following the communicative and collaborative development of planning practices, participatory PSS to facilitate stakeholder engagement and interaction have also been developed (see, e.g., [11]). Planning support system functionality may vary depending on the selected user and planning tasks but typically include capabilities to acquire, store, analyze and visualize data [12]. This is achieved by integrating various computational tools that include, but are not necessarily limited to, geographical information and spatial modeling 
systems [13]. Although land-use models are necessary for planning decision support, aspatial models and information are also considered valuable and essential [14].

This study aims to demonstrate how systems engineering may be utilized to organize and facilitate the co-creative development of PSSs for sustainable regional and urban planning. The systems engineering SPADE (stakeholders, problems, alternatives, decisions, evaluation) methodology is applied in a model-based fashion to develop a problem structure for urban planning utilizing the SDGs. The article reports on an application of this approach in the climate, land-use, and transportation planning process (PAKT) in the Ålesund region, where a series of stakeholder involvement workshops were held to link the sustainable development goals to planning decisions.

In the following section, we elaborate on contemporary developments and challenges in PSS development before study methods are introduced in Section 3. Results from the problem structuring exercise are presented in Section 4 and further discussed in Section 5. Concluding remarks and further research are presented in Section 6.

\section{Background}

\subsection{Planning Support in Ill-Structured Contexts}

Although multiple PSSs have been developed to aid sustainable regional and urban development, land-use and transport practitioners still largely rely on conventional methods, tools, and techniques in their everyday practice. Several scholars have explored this mismatch between the supply and demand of PSSs, often referred to as the implementation gap in PSS science $[15,16]$. In surveying planning practitioners and PSS users in the Netherlands, Te Brömmelstroet [17] found that "soft issues" such as lack of transparency, poor communication value, and low user-friendliness were considered primary bottlenecks for tool implementation. These findings were echoed in a study performed by Vonk and Geertman [18]. They identified challenges related to insufficient instrument quality and insufficient diffusion in planning practice, and low user acceptance. As a result of these shortcomings, PSSs often fail to support planning practitioners and other stakeholders in strategy-making processes [15].

The well-structured environment offered by PSSs is in stark contrast to the complex and dynamic planning and problem-solving processes at the strategic level [15]. According to Pidd [19], problems may be classified according to the level of stakeholder agreement on what the problem is and how it may be solved. Where there exists consensus on both, problems are merely puzzles; identifying a course of action is a matter of identifying the best option within the given context. At the other extreme, we find messes where stakeholders disagree on the problem and how these (different) problems should be solved. In between, we have problems where a unified problem definition is achievable, but work is required to formulate the problem and its potential solutions. Rittel and Webber [20] argue that planning problems are wicked in that it is impossible to achieve a definite answer to what the problem is and how it may be solved. A key property of wicked problems is that they are never definitely formulated. The problem and solutions emerge gradually among stakeholders through a continuous process of judgment, argument, and negotiation [20].

In order to offer a decision aid in these ill-structured contexts, PSS developers need to approach planning problems more holistically. In their summary of planning support science advancements and challenges, Geertman and Stillwell [16] assert that development in instrumentation needs to be supplemented with the continued research on the dimensions of application and governance to move beyond the former technology-driven approach in PSS. The application aspect pertains to the object-oriented goal of planning support and covers the content of planning and the objectives to be achieved. Governance aspects, in turn, relate to planning practices and processes by which these objectives are achieved [16]. This paper targets both the application and governance dimensions of planning explicitly using systems engineering to determine what sustainable urban development is and how it may be structured within a strategic planning context. This approach permits specify- 
ing the problems a PSS must solve in an open, structured manner, outside the realm of technology and its current limitations.

\subsection{Sustainable Urban Planning at the Strategic Level}

The planning context explored in this study is the establishment of a regional land-use and transportation master plan. Planning tasks at this level requires gathering and metabolizing information from various repositories to address multiple interrelated themes. The planning proposal should present key trends and development patterns in the region and identify preferable strategies and policies to support sustainable growth. This entails specifying guidelines and principles for land-use change and the development of transportation infrastructure and mobility services. In scoping and preparing the proposal, planners need to engage a wide range of planning stakeholders and facilitate their expression of opinions, perspectives, and expertise.

The case study presented in this paper follows a regional master plan process. In 2019, Ålesund, Giske, and Sula municipalities, commonly referred to as the Ålesund region, decided to jointly develop an inter-municipal master plan for climate, land-use, and transportation planning processes (abbreviated PAKT). The municipalities are located on the west coast of Norway and cover an area of $731 \mathrm{~km}^{2}$. The municipalities are interlinked as their 84,000 residents live, work and utilize services across municipal borders. An important objective in PAKT is to identify strategies to achieve the SDGs [21]. This is also considered a challenge as planners need to operationalize and link SDGs to their planning strategies in a meaningful and consistent manner.

While PAKT is inter-municipal, it links to the Norwegian planning hierarchy by providing a thematic input to each municipality's social master plans, as shown in Figure 1. The preparation of PAKT follows a four-stage process that takes place over two years. The first step involves developing a planning program that describes the current situation in the planning area pertinent to the theme, including objectives, conflicts, and future scenarios, and the need for further knowledge to support the planning process. This program was developed and adopted by the municipalities in early 2020. Next, the practitioners develop the knowledge basis and planning proposal, which outlines high-level strategies and guidance for further adoption at the municipal level. While the resulting document is not legally binding for the municipalities, it provides guidance for subsequent planning, states how areas should be utilized, and details special considerations and guidance. The draft planning proposal is currently under development and will be announced for public consultation during 2021. Once all interested parties and stakeholders have provided their inputs to the proposal, a revised proposal will be adopted by the municipalities in 2022 .
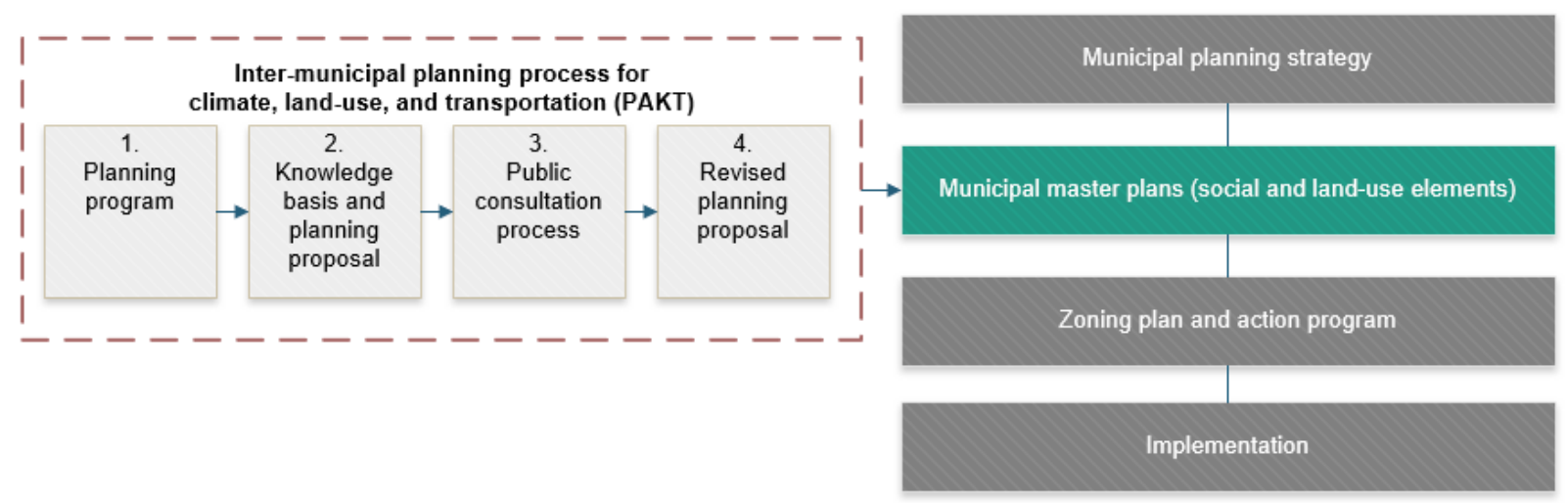

Figure 1. The climate, land-use, and transportation planning (PAKT) process and the municipal planning hierarchy, modified from $[21,22]$. 


\section{Method}

\subsection{Methodology: Systems Engineering as an Integrative Framework}

Systems engineering may be viewed both as a discipline and a process. As a discipline, it provides a basis for designing and applying systems from a holistic perspective [23]. As a process, it entails a systematic, top-down, iterative approach to system design, development, and deployment [23-25]. While initially developed to handle large-scale complex technical systems, it has evolved to support problem-solving in socio-technical systems [24].

The systems engineering SPADE methodology developed by Haskins [24] is derived from essential systems engineering processes to offer a generic, jargon-free framework for problem-solving. The acronym is built on the steps of the methodology, which encompasses defining and analyzing stakeholders, problems, alternatives, decision-making, and continuous evaluation. The methodology has been applied in multiple problem-solving efforts, with recent examples from applications to support bioeconomy transitions [26] and digital twin development of offshore cranes [27]. In [28], SPADE is used to develop a problem structure for marine emission reduction technology acquisitions. In this article, we deploy the methodology in the same manner, with the objectives of structuring planning decisions and reorienting them according to the SDGs. Table 1 summarizes the steps of SPADE and its application in our case study.

Table 1. The SPADE methodology applied to planning problem structuring, adapted from [24,28].

\begin{tabular}{cl}
\hline Step & \multicolumn{1}{c}{ Inquiry } \\
\hline $\mathrm{S}$ & Stakeholders: Who are the key stakeholders to the planning process? \\
$\mathrm{P}$ & $\begin{array}{l}\text { Problems: What are the stakeholder sustainability objectives and criteria and how do } \\
\text { they link to the SDGs? }\end{array}$ \\
$\mathrm{A}$ & $\begin{array}{l}\text { Alternatives: What are the alternative strategies, policies and measures that may be } \\
\text { implemented to achieve the objectives? }\end{array}$ \\
$\mathrm{D}$ & $\begin{array}{l}\text { Decisions: How do alternative courses of action comparatively evaluate towards the } \\
\text { stated objectives? }\end{array}$ \\
$\mathrm{E}$ & Evaluation: Continuous effort in, between and across all steps. \\
\hline
\end{tabular}

Identifying planning stakeholders is the first step of the approach. These are actors who influence and/or are influenced by the decisions at hand, in our case, the decisions and outcomes of the planning process. Stakeholders may be classified in several ways, e.g., considering their influence [29], but a practical approach is to differentiate between primary and secondary stakeholders [30]. In our study, we define a primary stakeholder as an individual or group directly involved in the planning process. Secondary stakeholders are additional individuals or groups whose interests are influenced by the outcomes of the planning process, resulting from interaction among primary stakeholders.

Next, stakeholder problems need to be analyzed. In a problem structuring context, this translates to their values, objectives to be achieved, and the partial ways they may be described through criteria [31-33]. If planning objectives are not already based on SDGs, they are reoriented in this step. This also entails identifying and linking objectives and criteria to measurable SDG-based indicators.

The third step requires formulating alternative courses of action to achieve the stated objectives. In a planning context, the level of detail in possible alternatives depends on the maturity of the planning process. High-level strategies are usually formulated at the initial stage before more detailed policies and measures are identified. In our approach, we attempt to structure these alternatives in a hierarchical manner. Once stakeholders, problems, and alternatives are identified, a decision analytical effort may be initiated. This requires collecting data to understand how alternative courses of action affect SDGs targeted in previous steps. In this article, we provide a linked problem structure to outline the decision step. Evaluation is performed within, between, and across all steps. 
Stage 1:

Problem structure development

\subsection{Stakeholder Focus Groups and Workshops}

In order to inform the problem structure and support its verification and validation, a series of stakeholder workshops were held during 2020. The workflow of the stakeholder involvement process in developing the problem structure for PAKT is shown in Figure 2. The process was initiated with scoping workshops held with a wide range of stakeholders representing the municipal, county, and state agencies to provide high-level expectations to the participatory planning support tool and ideation on its potential use in the PAKT planning.

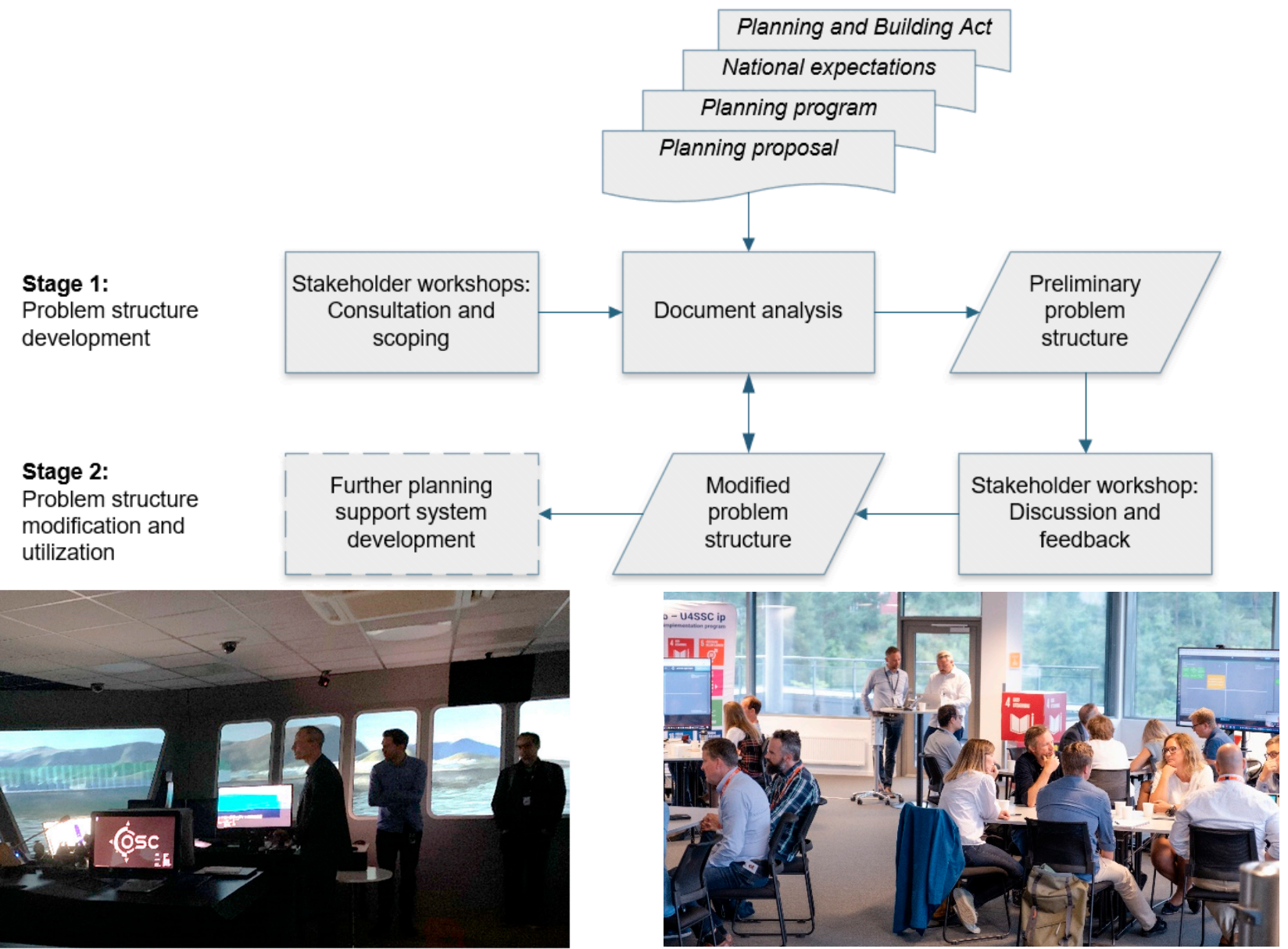

Figure 2. Stakeholder workshops in the PAKT problem structuring process.

The problem structuring process was continued through document analysis, where critical planning documents for the PAKT process were used to provide an initial problem structure. These encompass the Planning and Building Act, [34] which regulates planning activities, the National Expectations Regarding Regional and Municipal Planning [35], and the PAKT planning program [21]. This was presented in another stakeholder workshop for stakeholder feedback and inputs. Based on this exercise, a modified problem structure was developed. This structure was updated as the planning proposal [36] was presented.

\section{Results}

\subsection{Stakeholders}

The planning process for climate, land-use, and transportation involves many stakeholders representing various interests, viewpoints, and expertise pertinent to the process and decisions. We may divide these stakeholders into three main groups, as shown in Figure 3. 


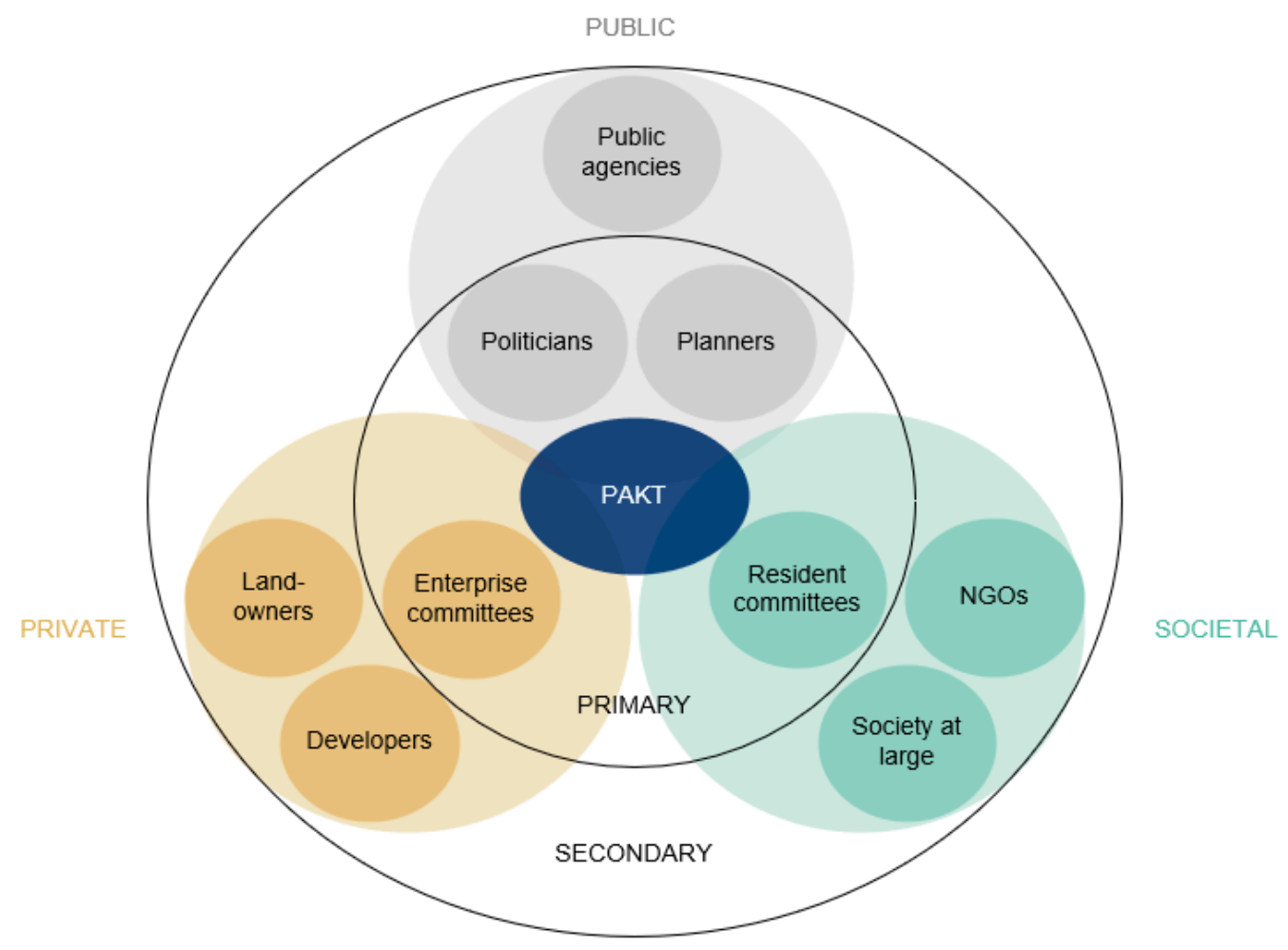

Figure 3. Stakeholders in the PAKT planning program.

Firstly, the public sector encompasses both the administrative and political resources necessary to develop and implement planning strategies and policies. In this group, we find the planners, politicians, and other state agencies that develop, decide, and support the planning processes. Planners and politicians are considered primary public stakeholders as they are directly and continuously engaged in the process as the PAKT strategies mature.

Next, we have stakeholders in the private sector, which influence and are influenced by planning decisions. While land-use policies may strongly influence landowners and developers, their involvement is less direct at the initial strategic level. In PAKT, enterprise committees representing private interests are established and hold regular meetings to provide direct feedback to planning documents. Due to their direct involvement, they are considered primary stakeholders.

Finally, we have the wider societal stakeholders, with residents, the society at large, and others represented through interest organizations. Residents are represented through various committees that provide feedback to PAKT during the planning process. They may therefore be considered primary stakeholders.

\subsection{Problems}

The objectives of the PAKT program set out the goals that the proposed PAKT plan and subsequent adoption of the plan in spatial and transport planning should strive to achieve. The planning program, draft proposals, and stakeholder feedback resulted in the objectives hierarchy in Figure 4. Eight initial objectives were distilled to four objectives with sub-objectives throughout this process. In the initial planning program, objectives were formulated without explicit links to the SDGs. Through the problem structuring process and subsequent draft plan proposal, SDGs pertinent to each objective were identified and formulated. 


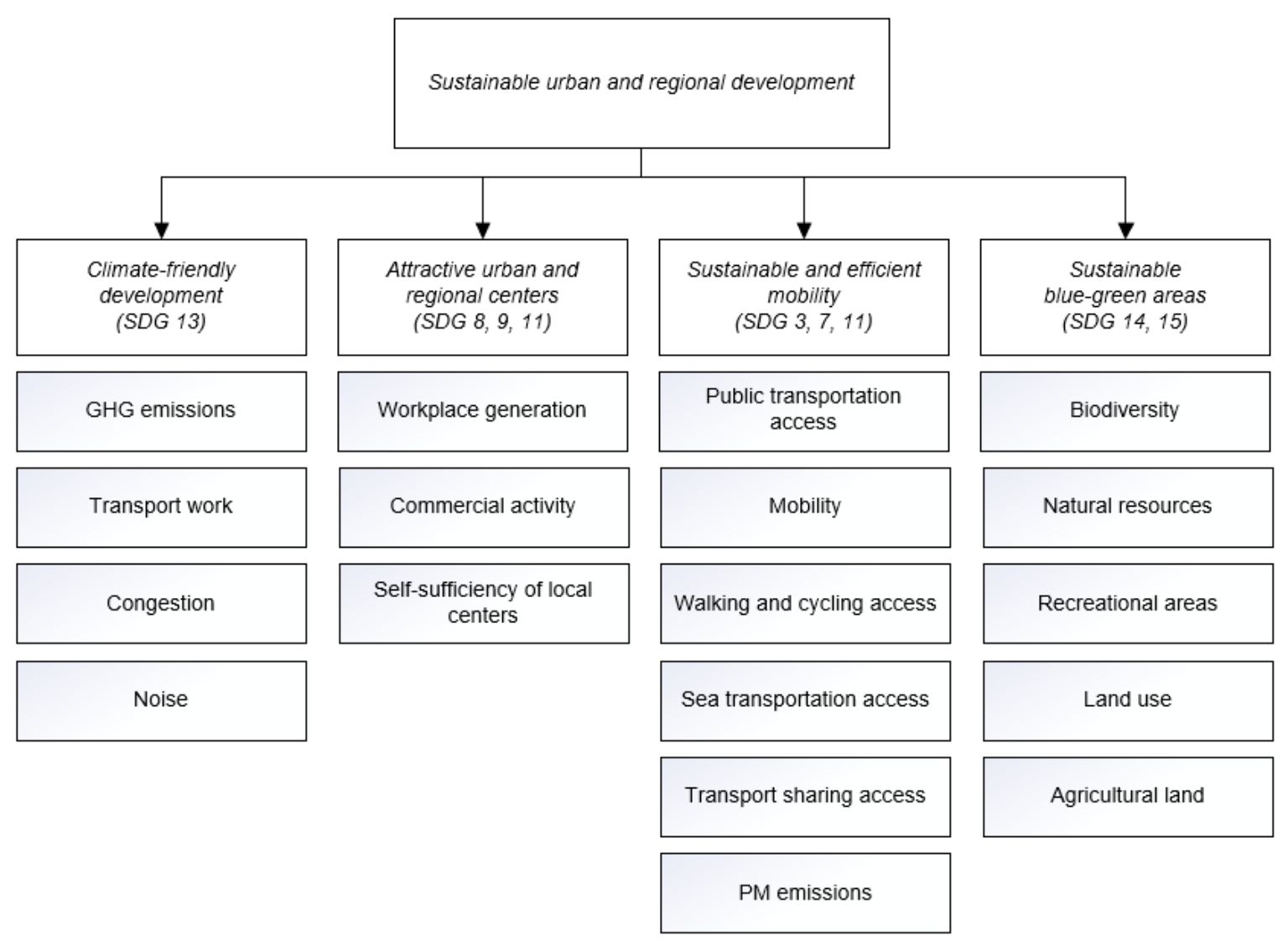

Figure 4. Structured objective hierarchy, derived from the PAKT planning program.

In order to operationalize objectives, they were linked to SDG-based indicators, as displayed in Figure 5. The United 4 Smart Sustainable Cities (U4SSC) indicator set [37] was used as an initial framework for providing indicators as the municipalities had recently performed self-assessment using this framework [38]. This permitted using existing data repositories and analytical models established in the municipalities to support planning decisions. The mapping between indicators and PAKT objectives helped identify which objectives were already covered and which objectives needed new indicators. The exercise showed that most of the mobility-related objectives, and anthropocentric land-use objectives, were well covered. Meanwhile, there was a lack of indicators to evaluate ecological and economic impacts from land use. As a result, it was decided to further develop indicators to accommodate the assessment of these objectives in subsequent work.

\subsection{Alternatives}

While the decisions following from the PAKT document will continue to be implemented in the period for which it has been adopted, the document itself also decides on some high-level strategies and policies for area development and lower-level measures to be implemented, as shown in Figure 6. These decisions will propagate through the planning hierarchy, ultimately providing the frames for day-to-day decisions made by planners. At the highest level in PAKT, we find the land-use strategies. These provide the rules for land-use in the region over the period, such as where residential and commercial growth will take place and implicitly, the land to be conserved. The PAKT document also provides a set of measures that may be further defined within the high-level land-use change strategies, i.e., area-focused measures concerning site selection for residential and commercial development and location of public services. We may also identify a set of transport-focused measures that aim to support sustainable transport within the region. 


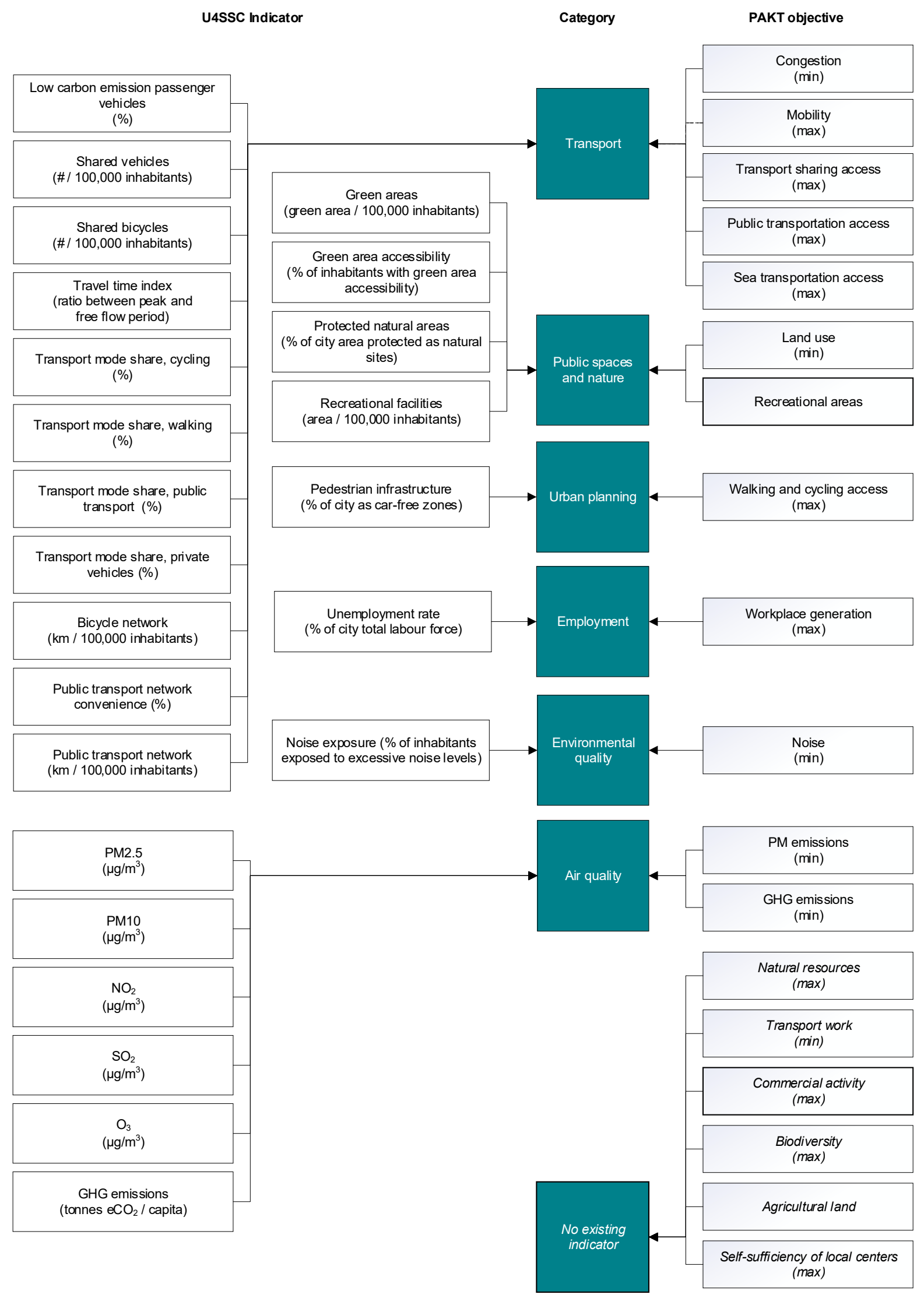

Figure 5. Linking objectives in the PAKT planning program to SDG-based KPIs. 

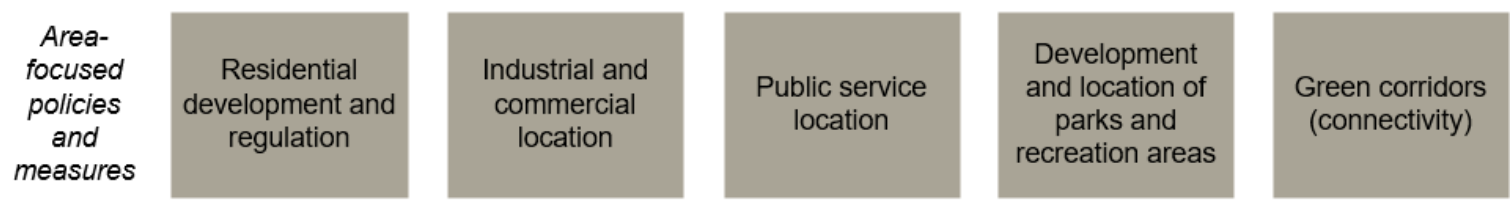

Transportfocused policies and measures
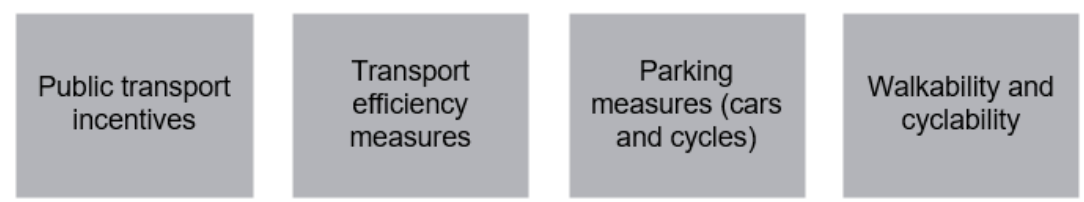

Power supply and charging infrastructure

Figure 6. Decision hierarchy derived from the PAKT planning proposal.

During the second stakeholder workshop, high-level land-use strategies were identified as central to all further spatial and transport planning, as shown in Figure 7. These strategies determine the principles for regional development and therefore have a high impact on all the identified objectives. Based on the planning proposal, four main options were identified on a continuum from centralization to decentralization. The first planning strategy is based on monocentric concentration, where land-use change takes place in a few select hubs, e.g., the centers in each of the three municipalities. The policy entails that all residential, commercial and public service development occur in or close to the hubs to provide high-density service centers. Locating residential areas in the vicinity of these areas may also reduce transport work and associated negative impacts. The second strategy is a more polycentric development, where multiple existing hubs are used as a basis for further regional development. This opens up opportunities for multiple types of hubs within each municipality, e.g., regional, district, and local hubs that are established. The third strategy is to perform no changes to existing strategies in PAKT, i.e., to continue the current plans each municipality has adopted. While these plans are not developed for regional efficiency but rather to optimize development within a smaller geographic area, the planners expected this policy alternative as pointing towards a more decentralized type of policy. The fourth and final strategy option is to deregulate spatial plans for the region, essentially permitting all land-use change to take place wherever municipalities, landowners, developers, and other commercial interests see fit. In this option, costs are the primary driver for site selection of residential development as well as the location of public and private services.

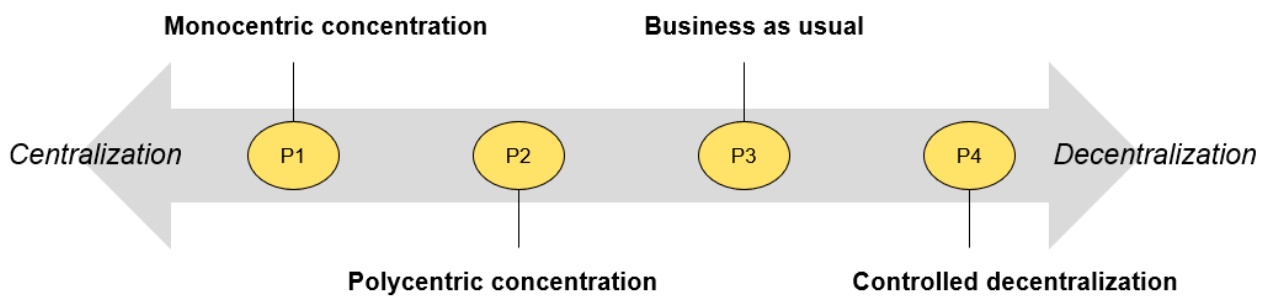

Figure 7. High-level land-use change strategies in the PAKT program and proposal.

\subsection{Decisions}

As part of planning decision-making, it is also necessary to evaluate how planning strategies and other measures comparatively perform against the stated objectives. This task would require further specifying model parameters and delimiting the decision problem temporally and spatially to perform a policy evaluation. Figure 8 is however 
useful as it shows the problem structure derived from the SPADE process to support planning decision-making. This structure will form the basis for evaluation tasks to be performed by a PSS to support spatial and transport planning in Ålesund, Giske, and Sula municipality as part of the Smart Plan project. The further design of the planning support tool also warrants systems engineering techniques, as it is necessary to identify user needs and requirements for the tool before defining its function and architecture.

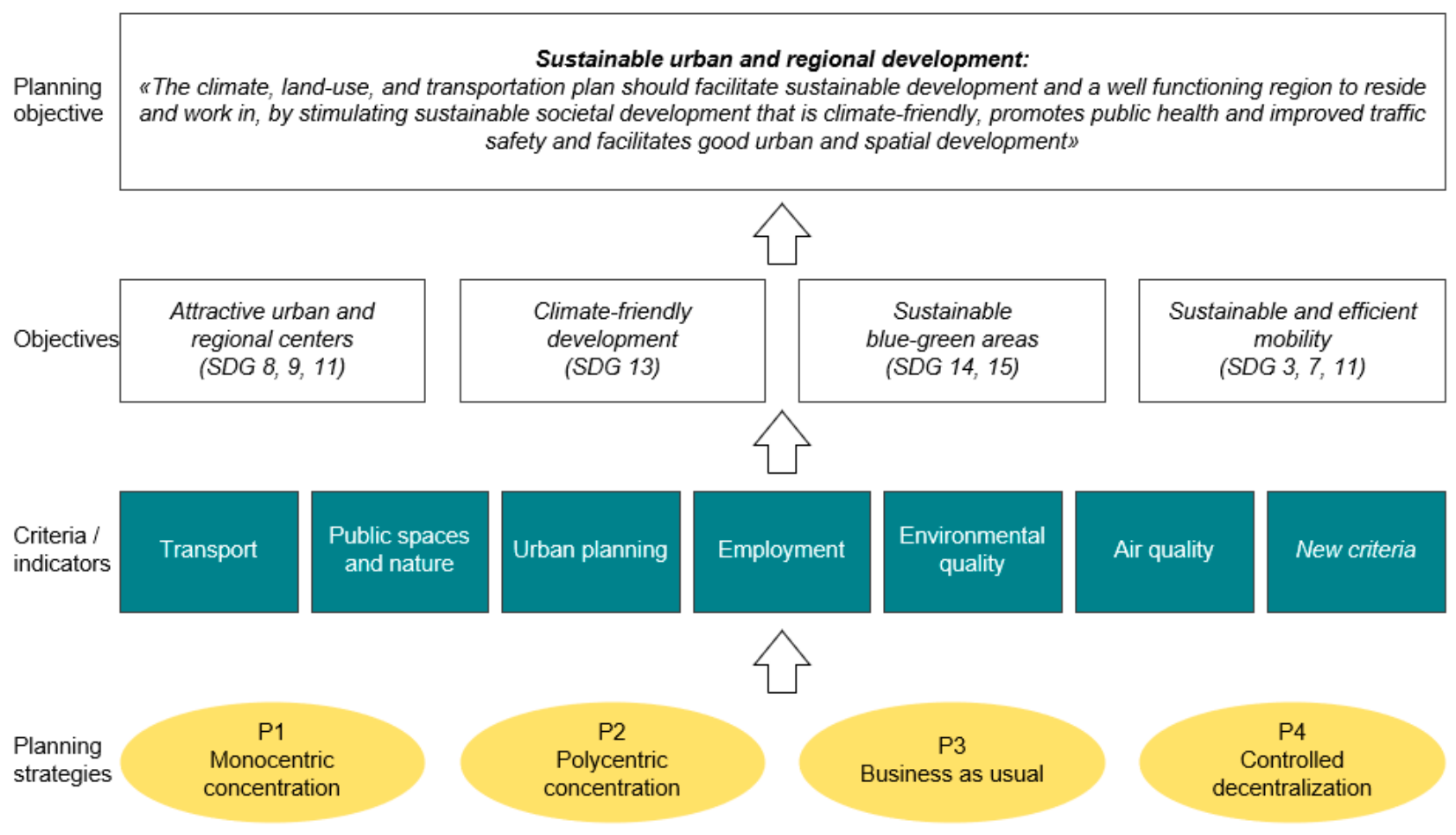

Figure 8. High-level problem structure for PAKT.

\subsection{Evaluation}

Evaluation is a continuous task performed in and between each step in the systems engineering SPADE method. As part of the stakeholder involvement process, feedback was given for each element of the problem structure during workshops to update and improve it. The within-step evaluation was performed by checking consistency with planning documents and correcting any misinterpretations through stakeholder dialogue. Consistencies across steps were also checked by tracing between models.

\section{Discussion}

\subsection{Workability of Systems Engineering in Planning Problem Structuring}

The application of systems engineering to establish a problem structure for sustainable urban planning demonstrates how consistent and traceable representations of an initially complex planning context may be achieved. The approach generates models elicited from and with stakeholders that help clarify the key planning context elements and their interrelationships.

While the literature is abundant with PSS tool descriptions, there is little knowledge about how to scope these tools properly. This requires moving beyond the domain of information and communication technology to consider the dimensions of application and governance [16]. SPADE enables PSS developers to gain a comprehensive understanding of the themes and issues that practitioners and planning stakeholders handle. This may be useful in establishing explicit and justifiable thoughts on tool scoping.

The approach also proved useful in engaging a wide range of planning stakeholders in a joint problem structuring effort. As the approach is jargon-free and intuitive, it presents 
a pedagogical frame for stakeholder involvement and co-creative problem-solving. The model-based implementation in the case study also proved practical as stakeholders easily could reflect upon and adjust models during and between workshop sessions. As models are sequenced according to the steps of SPADE, navigation between models was easily facilitated during discussions.

\subsection{Operationalizing and Integrating the Sustainable Development Goals in Planning}

The case study also demonstrates how explicit consideration of SDGs in the planning context may be achieved. While SDG-based planning was stated as an essential objective of the planning process in initial planning documents [21], they were not directly linked to planning objectives and strategies. This linkage was made possible once the problem structure was established. As this reorientation of objectives according to SDGs was made, it was also possible to link objectives to measurable criteria and indicators, which was another stated objective in the planning documents.

The case study utilized and linked an existing SDG indicator framework [37] to planning strategies, which allowed us to use a globally harmonized system. The model traceability rapidly helped identify entities for which new indicators were required. This ability to structure existing information and identify missing elements shows the benefit of creating a consistent model-based problem structure.

Although a specific indicator framework was operationalized in the case study, the systems engineering approach may also be used in instances where new indicators need to be developed. Stakeholders and experts could either be engaged to help synthesize new indicators or help sort and select indicators from a predefined set.

\subsection{Theoretical and Practical Limitations}

The models generated from the problem structuring exercise reported in this paper provide a basis for further synthesis of a PSS for strategic planning in the case study region. As each planning process and region is unique, the structured outputs are also idiosyncratic to the particular context in which they are developed [15]. The transferability of models between planning contexts may therefore be low. However, models may be practical in inspiring, comparing, and contrasting problem structures across planning contexts.

This limitation of model validity may also apply to the same region over time. As planning is a constantly evolving process, stakeholders' ideas, opinions, and perspectives may change, and new problems may emerge [16]. Therefore, a problem structure should not be considered a permanent representation of the planning context but rather as a snapshot at a specific point in time. SPADE is a cyclical methodology, and the reported procedure may be repeated with regular intervals to update and reorient the structured elements as needed.

Problem structuring and decision support literature highlights the need to create hierarchies with unique and non-overlapping objectives which reflect the fundamental values of stakeholders [31,39]. This is particularly important when alternatives are to be comparatively evaluated using formal models. The objectives and indicators established in Figure 5 have not been scrutinized for this purpose. Further iterations using SPADE could be used to validate the objectives and indicators against this formal requirement. This is a natural step in the continued work of synthesizing a PSS.

The reported application of systems engineering focused on structuring the decision context for planning stakeholders. While this provides a common frame of reference for main planning themes, objectives, and strategies, further tool synthesis must also build on extensive mapping of the practical context of the tool itself. This warrants its own problem structuring that focuses on PSS users and the tasks they need to perform in addressing planning decision problems. This subsequent step in the synthesis process could potentially also be explored from a systems engineering approach, where user needs and requirements are defined to further specify the PSS functions and architecture. 


\section{Concluding Remarks}

In this article, we have demonstrated the use of systems engineering to establish a problem structure to initiate the synthesis of a participatory planning support system (PSS) for sustainable regional planning. The systems engineering SPADE methodology has been applied in a model-based way to define and link sustainable development goals (SDGs) in a practical planning case involving multiple planning stakeholders. The case study has demonstrated that the approach is applicable in generating consistent and traceable representations of an initially ill-structured context and practical for engaging stakeholders in a co-creative problem structuring exercise. The model-based approach to problem structuring also proved practical in integrating and operationalizing the SDGs by linking them to indicators and planning strategies.

While the workability of the approach is demonstrated for the given context, additional applications should be made to further test the applicability and robustness of the approach across regions, planning domains, and planning levels. Mechanisms and procedures for updating problem structures within and across planning cycles would also prove useful to avoid static representations of dynamic planning environments. Further synthesis of PSSs requires additional mapping of user needs and requirements. Exploring the translation of planning problem structures to tool functions and architecture is a critical topic for further research.

Author Contributions: Conceptualization, D.M.A.; methodology, D.M.A.; validation, D.M.A. and A.A.; formal analysis, D.M.A.; writing — original draft preparation, D.M.A. and A.A.; writing-review and editing, D.M.A. and A.A. All authors have read and agreed to the published version of the manuscript.

Funding: This research was funded by The Research Council of Norway and performed as part of the Smart Plan project, grant number 310056 and the SUSTRANS project, grant number 267887.

Institutional Review Board Statement: Not applicable.

Informed Consent Statement: Not applicable.

Data Availability Statement: The data presented in this study are available in the article.

Acknowledgments: The authors wish to thank urban planners, architects, and managers in the Ålesund region for their participation in and inputs to the case study. We also wish to thank project partners and colleagues from the Sustainability Analytics research arena at NTNU, and colleagues at Volda University College and Offshore Simulator Centre for feedback during the process. The authors wish to express their sincere gratitude to three anonymous reviewers for their useful suggestions on how to improve the quality of the paper.

Conflicts of Interest: The authors declare no conflict of interest.

\section{References}

1. OECD. A Territorial Approach to the Sustainable Development Goals; OECD: Paris, France, 2020.

2. Global Taskforce of Local and Regional Governments; UN Habitat; UNDP. Roadmap for Localizing the SDGs: Implementation and Monitoring at Subnational Level. 2016. Available online: https://www.uclg.org/sites/default/files/roadmap_for_localizing_the_ sdgs_0.pdf (accessed on 20 January 2021).

3. Asker Municipality. From Global Goals to Local Action-How We Implement the UN Sustainable Development Goals (SDGs) in Asker Municipality; Asker Municipality: Asker, Norway, 2020.

4. Lundberg, A.K.; Bardal, K.G.; Vangelsten, B.V.; Brynildsen, M.; Bjørkan, R.; Bjørkan, M.; Richardson, T. Strekk i Laget: En Kartlegging av Hvordan FNs Bxrekraftsmål Implementeres $i$ Regional og Kommunal Planlegging (Mind the Gap-Mapping How UN SDGs Is Implemented in Regional and Municipal Planning); Nordlandsforskning-Nordland Research Institute: Bodø, Norway, 2020.

5. Kirst, E.; Lang, D.J. Perspectives on Comprehensive Sustainability-Orientation in Municipalities: Structuring Existing Approaches. Sustainability 2019, 11, 1040. [CrossRef]

6. Valencia, S.C.; Simon, D.; Croese, S.; Nordqvist, J.; Oloko, M.; Sharma, T.; Buck, N.T.; Versace, I. Adapting the Sustainable Development Goals and the New Urban Agenda to the city level: Initial reflections from a comparative research project. Int. J. Urban Sustain. Dev. 2019, 11, 4-23. [CrossRef]

7. Krellenberg, K.; Bergsträßer, H.; Bykova, D.; Kress, N.; Tyndall, K. Urban Sustainability Strategies Guided by the SDGs-A Tale of Four Cities. Sustainability 2019, 11, 1116. [CrossRef] 
8. Geertman, S.; Stillwell, J. Planning support systems: An inventory of current practice. Comput. Environ. Urban Syst. 2004, 28, 291-310. [CrossRef]

9. Geertman, S.; Stillwell, J. Handbook of Planning Support Science; Edward Elgar Publishing: Northampton, UK, 2020.

10. Flacke, J.; Shrestha, R.; Aguilar, R. Strengthening Participation Using Interactive Planning Support Systems: A Systematic Review. ISPRS Int. J. Geo Inf. 2020, 9, 49. [CrossRef]

11. Pettit, C.; Shi, Y.; Han, H.; Rittenbruch, M.; Foth, M.; Lieske, S.; Nouwelant, R.V.D.; Mitchell, P.; Leao, S.; Christensen, B.; et al. A new toolkit for land value analysis and scenario planning. Environ. Plan. B Urban Anal. City Sci. 2020, 47, 1490-1507. [CrossRef]

12. Klosterman, R.E. Planning support systems: A new perspective on computer-aided planning. J. Plan. Educ. Res. 1997, 17, 45-54. [CrossRef]

13. Geertman, S.; Stillwell, J. Planning Support Systems in Practice; Springer: Berlin, Germany, 2003.

14. Couclelis, H. "Where has the future gone?" Rethinking the role of integrated land-use models in spatial planning. Environ. Plan. A 2005, 37, 1353-1371. [CrossRef]

15. Te Brömmelstroet, M. Towards a pragmatic research agenda for the PSS domain. Transp. Res. Part A Policy Pract. 2017, 104, 77-83. [CrossRef]

16. Geertman, S.; Stillwell, J. Planning support science: Developments and challenges. Environ. Plan. B Urban Anal. City Sci. 2020, 47, 1326-1342. [CrossRef]

17. Te Brömmelstroet, M. Equip the warrior instead of manning the equipment: Land use and transport planning support in the Netherlands. J. Transp. Land Use 2010, 3, 25-41. [CrossRef]

18. Vonk, G.; Geertman, S. Improving the Adoption and Use of Planning Support Systems in Practice. Appl. Spat. Anal. Policy 2008, 1, 153-173. [CrossRef]

19. Pidd, M. Tools for Thinking: Modelling in Management Science, 2nd ed.; Wiley: Chichester, UK, 2003.

20. Rittel, H.W.J.; Webber, M.M. Dilemmas in a general theory of planning. Policy Sci. 1973, 4, 155-169. [CrossRef]

21. Region Ålesund. Planprogram. Plan for Areal, Klima og Transport i Ålesundsregionen (Planning Program. Plan for Area, Climate and Ransportation in the Ålesund Region); Region Ålesund: Ålesund, Norway, 2020.

22. Ministry of Local Government and Modernisation. Municipal Planning. 2014. Available online: https://www.regjeringen.no/ en/topics/plan-bygg-og-eiendom/plan--og-bygningsloven/planning/engelsk-test---planning-in-norway/engelsk-test----2 /id710310/ (accessed on 20 January 2021).

23. INCOSE. Systems Engineering Handbook: A Guide For System Life Cycle Processes and Activities; Ringgold Inc.: Beaverton, OR, USA, 2006.

24. Haskins, C. Systems Engineering Analyzed, Synthesized, and Applied to Sustainable Industrial Park Development; Norges TekniskNaturvitenskapelige Universitet: Trondheim, Norway, 2008.

25. Blanchard, B.S.; Fabrycky, W.J. Systems Engineering and Analysis; Pearson: Boston, MA, USA, 2011.

26. Palmer, E.; Burton, R.; Haskins, C. A Systems Engineering Framework for Bioeconomic Transitions in a Sustainable Development Goal Context. Sustainability 2020, 12, 6650. [CrossRef]

27. Fotland, G.; Haskins, C.; Rølvåg, T. Trade study to select best alternative for cable and pulley simulation for cranes on offshore vessels. Syst. Eng. 2020, 23, 177-188. [CrossRef]

28. Aspen, D.M.; Haskins, C.; Fet, A.M. Application of systems engineering to structuring acquisition decisions for marine emission reduction technologies. Syst. Eng. 2018, 21, 388-397. [CrossRef]

29. Mitchell, R.K.; Agle, B.R.; Wood, D.J. Toward a Theory of Stakeholder Identification and Salience: Defining the Principle of Who and What Really Counts. Acad. Manag. Rev. 1997, 22, 853-886. [CrossRef]

30. Clarkson, M.B.E. A Stakeholder Framework for Analyzing and Evaluating Corporate Social Performance. Acad. Manag. Rev. 1995, 20, 92-117. [CrossRef]

31. Keeney, R.L. Value-Focused Thinking: A Path to Creative Decisionmaking; Harvard University Press: Cambridge, MA, USA, 1992.

32. Belton, V.; Stewart, T.J. Multiple Criteria Decision Analysis: An Integrated Approach; Kluwer Academic: Boston, MA, USA, 2002.

33. von Winterfeldt, D.; Fasolo, B. Structuring decision problems: A case study and reflections for practitioners. Eur. J. Oper. Res. 2009, 199, 857-866. [CrossRef]

34. Ministry of the Environment. Planning and Building Act (2008). Act of 27 June 2008 No. 71 relating to Planning and the Processing of Building Applications (the Planning and Building Act) (the Planning Part). 2008. Available online: https://www.regjeringen.no/en/ dokumenter/planning-building-act/id570450/ (accessed on 20 January 2021).

35. Ministry of Local Government and Modernisation. National Expectations Regarding Regional and Municipal Planning 2019-2023.35; Ministry of Local Government and Modernisation: Oslo, Norway, 2019.

36. Region Ålesund. PAKT. Plan for Areal, Klima og Transport i Ålesundsregionen; Region Ålesund: Ålesund, Norway, 2021.

37. Smiciklas, J.; Prokop, G.; Stano, P.; Sag, Z. Collection Methodology for Key Performance Indicators for Smart Sustainable Cities; U4SSC: Geneva, Switzerland, 2017.

38. International Telecommunication Union (ITU). Verification Report-Ålesund, Norway; International Telecommunication Union: Geneva, Switzerland, 2020.

39. Keeney, R.L.; Raiffa, H. Decisions with Multiple Objectives: Preferences and Value Tradeoffs; Cambridge University Press: Cambridge, UK, 1993. 